\title{
Microbiological studies of the enterocolitis of Hirschsprung's disease
}

\author{
D Wilson-Storey, W G Scobie, K G McGenity
}

\begin{abstract}
The results of a prospective study of 20 cases of newly diagnosed Hirschsprung's disease (nine of whom developed enterocolitis) and 10 normal controls showed no variations in the bacterial flora (including Clostridium difficile) in the stools of the groups studied. Viral studies showed that rotavirus was present in the stools of seven of the nine cases of enterocolitis during the episode. We suggest that Hirschsprung's enterocolitis may have a complex infective aetiology and that rotavirus plays a part.
\end{abstract}

Hirschsprung's disease (congenital intestinal aganglionosis) is an important cause of functional intestinal obstruction in childhood occurring once in every 5000 live births. ${ }^{1}$ The most severe, potentially life threatening complication is Hirschsprung's enterocolitis, and it is estimated that $5 \%$ of patients with Hirschsprung's disease will die of it. It can occur at any time during the course of the disease, irrespective of age, sex, or method or timing of management, ${ }^{2-4}$ and is characterised by abdominal distension, diarrhoea, fever, and hypovolaemic shock. Vomiting is an uncommon feature. The diagnosis is made clinically and confirmed radiologically showing colonic dilatation, mucosal ulceration, gastrointestinal hypermotility and sometimes pneumatosis coli-although this is less common in Hirschsprung's than in necrotising enterocolitis.

The aetiology of Hirschsprung's enterocolitis is uncertain, although many theories have been advanced including proximal colonic dilatation with resultant mucosal ischaemia and bacterial invasion, ${ }^{5}$ and hypersensitivity to bacterial antigens. ${ }^{6}$ More recently, Clostridium difficile and its toxin have been implicated, ${ }^{78}$ although many healthy neonates and infants excrete toxin secreting $C$ difficile in their stools. ${ }^{910}$

The aim of this study was to assess prospectively the microbiological flora (bacterial and viral) in the faeces of newly diagnosed patients with Hirschsprung's disease to find out if any changes occurred in those who subsequently developed enterocolitis.

Subdepartment of The Children's Hospital, Western Bank Sheffield S10 2 TH D Wilson-Storey K G McGenity

Western General Hospital, Edinburgh W G Scobie

Correspondence to: Mr Wilson-Storey.

Accepted 4 June 1990 tis. Ten normal age and sex matched patients from the same hospital ward but no with gastrointestinal conditions (circumcision, orchidopexy, and external angular dermoid cystectomy) were also studied. No patient had suffered from, or had been in contact with, diarrhoea or vomiting before or during this admission to hospital.

\section{SPECIMENS}

Specimens of faeces were taken from all new cases of Hirschsprung's disease at their initial presentation for immediate bacteriological and viral studies to be carried out. In those who subsequently developed enterocolitis, stool samples were taken during and after the attack and similar studies carried out. Fluid collected during therapeutic colorectal lavage was also sent for study. Stools from control subjects were processed in the same way.

\section{CULTURES \\ Bacterial studies}

Various culture media were used to isolate potential pathogens and separate them from the large number of commensals that normally inhabit the gastrointestinal tract, including blood agar, MacConkey's agar, deoxycholate citrate agar, selonite broth, campylobacter media, and cycloserine cefoxitin fructose agar. $C$ difficile toxin was sought by enzyme linked immunosorbant assay (ELISA).

\section{Viral studies}

Viruses were cultured on tissue cultures. Rotavirus was specifically sought in each case by electron microscopy.

\section{Results}

There were 17 boys and three girls with ages ranging from 5 days to 2 years (mean 8.6 months). All cases were treated initially by fashioning of a defunctioning colostomy followed by anorectal myectomy (mean age 9 months), and anterior resection (mean age 11.4 months).

Nine cases subsequently developed enterocolitis, one before diagnosis of the Hirschsprung's disease and the remainder within one month of the defunctioning colostomy. Three had further episodes after anterior resection. There was no seasonal variation in incidence, five cases occurring during the winter, two during the summer, and two during the autumn. All responded to conservative management with intravenous fluids, parenteral antibiotics, and colorectal lavage. 
Microbiology of stool cultures in 20 patients with Hirschsprung's disease and 10 control subjects

\begin{tabular}{|c|c|c|c|c|c|}
\hline & \multicolumn{4}{|c|}{ No of positive cultures in patients with Hirschsprung's disease } & \multirow{3}{*}{$\begin{array}{l}\text { No of positive } \\
\text { cultures in } \\
\text { control subjects } \\
(n=10)\end{array}$} \\
\hline & \multirow{2}{*}{$\begin{array}{l}\text { Without enterocolitis } \\
(n=11)\end{array}$} & \multicolumn{3}{|c|}{ With enterocolitis $(n=9)$} & \\
\hline & & Before attack & During attack & After attack & \\
\hline $\begin{array}{l}\text { Coagulase negative staphylococcus } \\
\text { Escherichia coli } \\
\text { Streptococcus faecalis } \\
\text { Klebsiella spp } \\
\text { C difficile } \\
\text { Bacteriodes fragilis } \\
\text { C difficile toxin }\end{array}$ & $\begin{array}{r}10 \\
11 \\
8 \\
3 \\
6 \\
8 \\
5\end{array}$ & $\begin{array}{l}8 \\
8 \\
5 \\
4 \\
6 \\
6 \\
6\end{array}$ & $\begin{array}{l}9 \\
8 \\
4 \\
5 \\
7 \\
7 \\
6\end{array}$ & $\begin{array}{l}9 \\
9 \\
8 \\
4 \\
5 \\
7 \\
7\end{array}$ & $\begin{array}{r}10 \\
10 \\
8 \\
6 \\
6 \\
9 \\
5\end{array}$ \\
\hline
\end{tabular}

The results of the microbiological studies are shown in the table. None of the stool samples from the 20 patients with Hirschsprung's disease or the 10 controls grew any pathogenic organisms. Viral studies of the stools and of the fluid obtained after therapeutic colorectal washout during the episodes of enterocolitis, however, showed rotavirus in seven of the nine cases $(78 \%)$. No other pathogenic organisms were identified.

\section{Discussion}

Unlike previous studies, ${ }^{78}$ this study has failed to isolate any specific organism that could be implicated in the pathogenesis of Hirschsprung's enterocolitis. $C$ difficile was present in over half of the cases studied and there was no variation among the groups, thus confirming previous reports that this organism is a commensal within the infant gut. ${ }^{910}$ There were, however, more patients with $C$ difficile toxin in the stools in the enterocolitis group, which may indirectly implicate this organism.

Viral studies showed an interesting finding, in that rotavirus was isolated from the stools of seven of the nine patients who developed enterocolitis, despite not having been detected on initial investigation. Rotavirus is the commonest cause of gastroenteritis in childhood, having a peak incidence between 6 months and 3 years of age, and being most frequent during the winter. It is resistant to gastric acid and infects mature epithelial cells in the ileum, thus replicating and impairing absorptive and transfer functions and resulting in diarrhoea. Immunological defence against rotavirus is dependent upon IgA within the gut wall. Most babies have circulating maternal rotavirus antibodies at birth, but these decrease during the first six months of life, after which the child is susceptible to rotavirus infection. Breast feeding (maternal milk contains rotavirus antibody) gives some protection to the infant.

The findings of this study suggest therefore that rotavirus plays some part in the pathogenesis of Hirschsprung's enterocolitis, as there was no evidence of contact with rotavirus in these patients either before, during, or after their admission to hospital, and indeed the signs and symptoms of enterocolitis began outside the hospital environment in all cases. It seems unlikely that the episodes of enterocolitis were 'pure' rotavirus gastroenteritis, as in no case was vomiting a symptom.

We were, however, unable to explain from our results why these children were more susceptible -and subsequently overwhelmed-by this infection with generalised systemic illnesses whereas other children with the same underlying disease were not. It may be that the children who are prone to this complication have some underlying deficiency in host defence that allows them to be overcome by rotavirus or any other invading organism, as suggested by the number of patients with enterocolitis who had $C$ difficile toxins in their stools.

\section{CONCLUSIONS}

From these results we suggest that rotavirus may be implicated in the pathogenesis of Hirschsprung's enterocolitis, which may therefore have a complex infective aetiology. We recommend that children with Hirschsprung's disease undergo regular viral and bacterial stool culture at diagnosis and immediately if loose stools occur to enable early detection of infection. This would permit careful observation if the children were asymptomatic and prompt diagnosis and management to prevent progression of this potentially lethal condition.

The study was supported by the Peel Medical Research Fund.

1 Ehrenpreis T. Hirschsprung's disease. Chicago: Year Book Medical Publishers, 1970.

2 Khan O, Nixon HH. Results following surgery for Hirschsprung's disease. A review of three operations with reference to neorectal capacity, $\operatorname{Br} \mathcal{F}$ Surg 1980;67:436-8.

3 Kleinhaus S, Boley SJ. Hirschsprung's disease. A survey of the members of the surgical section of the American Academy of Pediatrics. I Pediatr Surg; 1979;14:588-97. 4 Frank JD, Nixodiatrics. F Pediatr Surg; 1979;14:588-97. disease. Analysis and conclusions for therapy. Prog Pediatr

5 Bill AH, Chapman N. The enterocolitis of Hirschsprung's disease: its natural history and treatment. Am $\mathcal{Y}$ Surg 1962 ; disease: its

6 Berry CL, Fraser GC. The experimental production of colitis in the rabbit with particular reference to Hirschsprung's disease. I Pediatr Surg 1968;3:36-42.

7 Thomas DFM, Fernie D, Malone M, Bayston R, Spitz L. Association between Clostridium difficile and enterocolitis in Hirschsprung's disease. Lancet 1982;i:78-9.

8 Thomas DFM, Fernie D, Malone M. Enterocolitis in Hirschsprung's disease: a controlled study of the etiologic role of Clostridium difficile. $\mathcal{F}$ Pediatr Surg 1986;21:22-5.

9 Holst E, Henlin I. Recovery of Clostridium difficile from children. Scan $\mathcal{f}$ Infect Dis 1981;13:41-5.

10 Rietra PJG, Slaterus KW. Clostridium toxin in the faeces of healthy children. Lancet 1978;ii:319. 